\title{
EXPANDING WAISTLINES A "Nutrition Transition" in China
}

KITSY SMITH

AS CHINA'S COFFERS HAVE SWELLED OVER THE PAST THREE DECADES, ITS CITIZENS' WAISTLINES HAVE ALSO EXPANDED. WESTERN GOODS AND LIFESTYLE HABITS ARE CONSISTENTLY BEING IMPORTED INTO THE ASIAN GIANT, INCLUDING THE OBESITY EPIDEMIC. CHINESE CHILDREN ARE PARTICULARLY SUSCEPTIBLE AND FUTURE GENERATIONS FACE TREMENDOUS HEALTH RISKS DESPITE MEDICAL ADVANCES. STATES AND INTERNATIONAL BODIES SUCH AS THE WORLD HEALTH ORGANIZATION ARE ALARMED AT THE DAMAGE OBESITY IS ALREADY PRODUCING. THE PRICE TAG TO TREAT THE HEALTH PROBLEMS ASSOCIATED WITH OBESITY AND THE RESULTING LOSS IN ECONOMIC PRODUCTIVITY IS STAGGERINC. WHILE THIS ESSAY USES CHINAAS A CASE STUDY TO EXAMINE THE CAUSES OF OBESITY AND ITS CONSEQUENCES, SOCIAL AND ECONOMIC HEALTH, THE GRIM REALITY IS THAT THIS PATTERN IS OCCURRING WORLDWIDE AS COUNTRIES DEVELOP AND THEIR PEOPLE ADOPT WESTERN "NUTRITIONAL" NORMS. 
China's remarkable economic growth over the past thirty years has been nothing short of a miracle. This advancement, however, comes with a price. Increased prosperity has brought a cultural and social desire for modern and western lifestyles, including western eating habits. "Nutrition transition," the spread of excessively-caloric meals and declining activity, is now saturating Asia. Though nowhere near the levels of obesity which the United States currently faces, China is headed in that dire direction unless action is taken by the government, food companies, and individuals. A concerted effort is required to avert the damaging public-health and economic costs of obesity. Since children are particularly vulnerable to this phenomenon, an unhealthy and less-productive future generation awaits China.

This paper proposes to look specifically at China in relation to the "nutrition transition." Although it is a worldwide phenomenon, China has a unique cultural and historic qualities which could facilitate the rise of obesity. 'These include both the fastest-growing economy and population in the world, a one-child policy, urban explosion, and cultural attitudes toward eating and fat. As China and the developing world in general rise to the economic and social status enjoyed by the West, caution and care must be taken to prevent the negative and harmful consequences which accompany this transition, particularly with regard to eating habits.

\section{HEALTH COSTS OF OBESITY}

Though relatively new to China, obesity is a familiar phenomenon in the West. According to Dr. Joseph Gigante, a pediatrician and professor at Vanderbilt University, "obesity is defined simply as too much body fat." Your body is made up of water, fat, protein, carbohydrates and various vitamins and minerals. Body fat is measured by body mass index (BMI) to determine obesity. If you have a BMI of thirty or higher, your extra weight is putting your health in danger. If you are Asian, your health may be at risk with a BMI of 27.5 or higher. The risks of obesity are numerous, and include "high blood pressure, high blood cholesterol,

\section{"The collision of newly affluent consumers with food companies eager to tap this emerging market has created the optimal conditions for a health crisis."}

diabetes, heart disease and stroke." Aptly described as “'globesity' ... the WHO [World Health Organization] estimates there to be at least three hundred million obese people worldwide" sixty million of which are United States ciizens.

The costs of obesity to the individual and society are staggering; Gigante warns that these include "decreased productivity, restricted activity, absenteeism, and bed days" from work as well as premature death. In fact, individuals who are 40 percent heavier than the recommended healthy weight level are "twice as likely to die prematurely as is an average-weight person." "ii Additionally, "medical expenses accounted for 9.I percent of total U.S. medical expenditures in 1998 and may have reached as high as $\$ 78.5$ billion (\$92.6 billion adjusted for inflation in 2002)." Although China currently spends only 5 percent of its gross national product (GNP) on obesity-related costs, "it's only a matter of time before ... spending catches up to that of the United States, which spends $17-20$ percent of its GNP on related costs," warns expert Barry Popkin. iii The money spent on medicine and care for an unhealthy population as well as the social and economic productivity losses caused by obesity could severely damage the awakening giant. Rather than face these losses and incur these costs, the Chinese government would be better serving its citizens and itself 
by taking measures now to prevent and solve the causes before dealing with the inevitable consequences of this real crisis. Medical costs and productivity loss for the "more than 169 million overweight adults, and [the] additional 26 million [who are] obese" will take their toll on this economic powerhouse, if they have not already. iv

\section{RISING INCOME LEVELS FUEL}

\section{UNHEALTHY EATING HABITS}

Obesity is a serious problem which, rather than being addressed and halted, is spreading eastward. It has been observed by the WHO that "as incomes rise and populations become more urban, diets rich in complex carbohydrates give way to more varied diets with a higher proportion of fats, saturated fats and sugars. At the same time, shifts towards less physically demanding

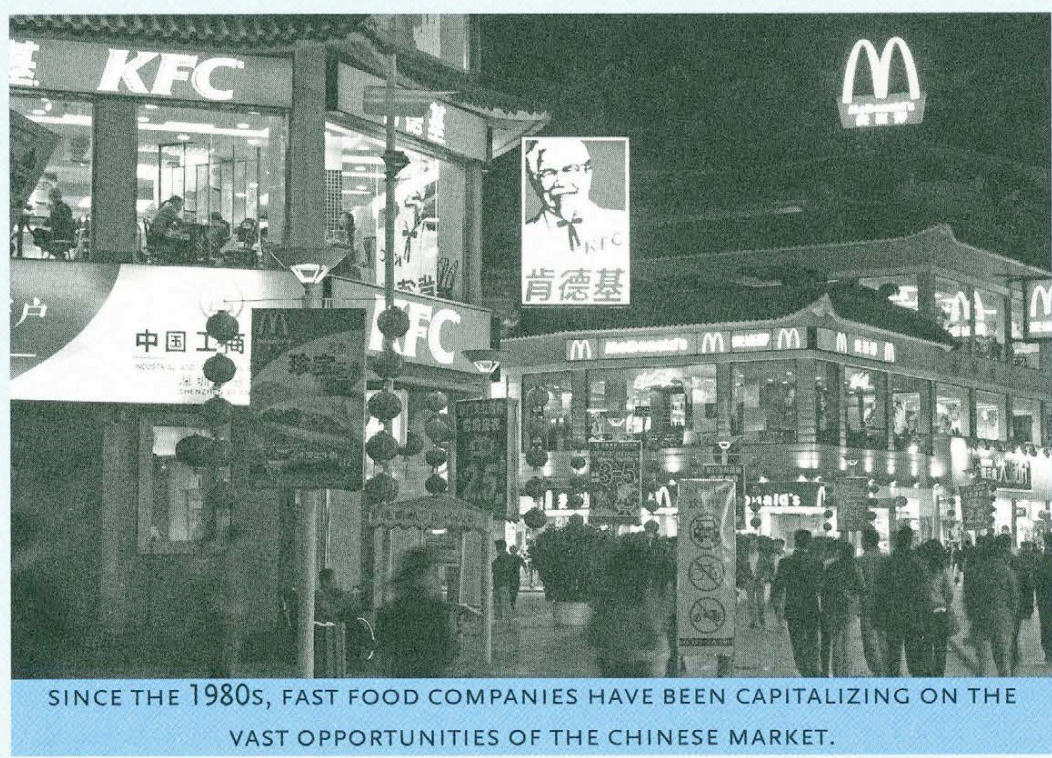
work have been

observed." The Chinese today enjoy greater economic prosperity and are experiencing urban expansion and growth. The introduction of willing consumers to dicretionary income and foreign food companies' eagerness to tap the potential of this emerging market has ceated the optimal conditions for a health crisis. Since joining the WTO organization in 200I, China has lowered protectionism and opened itself to foreign investors and businesses. The first Kentucky Fried Chicken Franchise opened in 1987 , and McDonalds quickly followed, opening its first restaurant in Beijing in 1992. The increase and spread of
McDonalds restaurants eastward is a perfect example of the "Nutrition Transition" phenomenon, and is modeled in Figure I.

Given that "every month, around a million or more "Chinese enter the hallowed ranks of the middle class," the rapid purchasing power of consumers has set off the "shift from eat-to-live to live-to eat," and testifies to the cultural experience of food as a "mode" and status rather than a survival necessity.vi The prevalence of "a predominantly commercially-driven environment that encourages consumers to eat and eat more, [along with the] vast array of restaurants [which] have opened in cities since the last decade," have resulted in an increase in "the share of household food expenditures spent on food away from home."vii

China's "transition from planned economy to market economy has brought about great political and cultural changes, which naturally lead to changes in value system ... when people begin to interact with each other in the market economy system, value consciousness becomes re-oriented [from ethics and politics] towards material benefits."viii The expansion and importance of the Chinese economy today has brought with it challenges and issues for the government and people it assists.

The problem remains, however, that the Chinese are consuming high fat, low nutrition foods such as meats, oils 


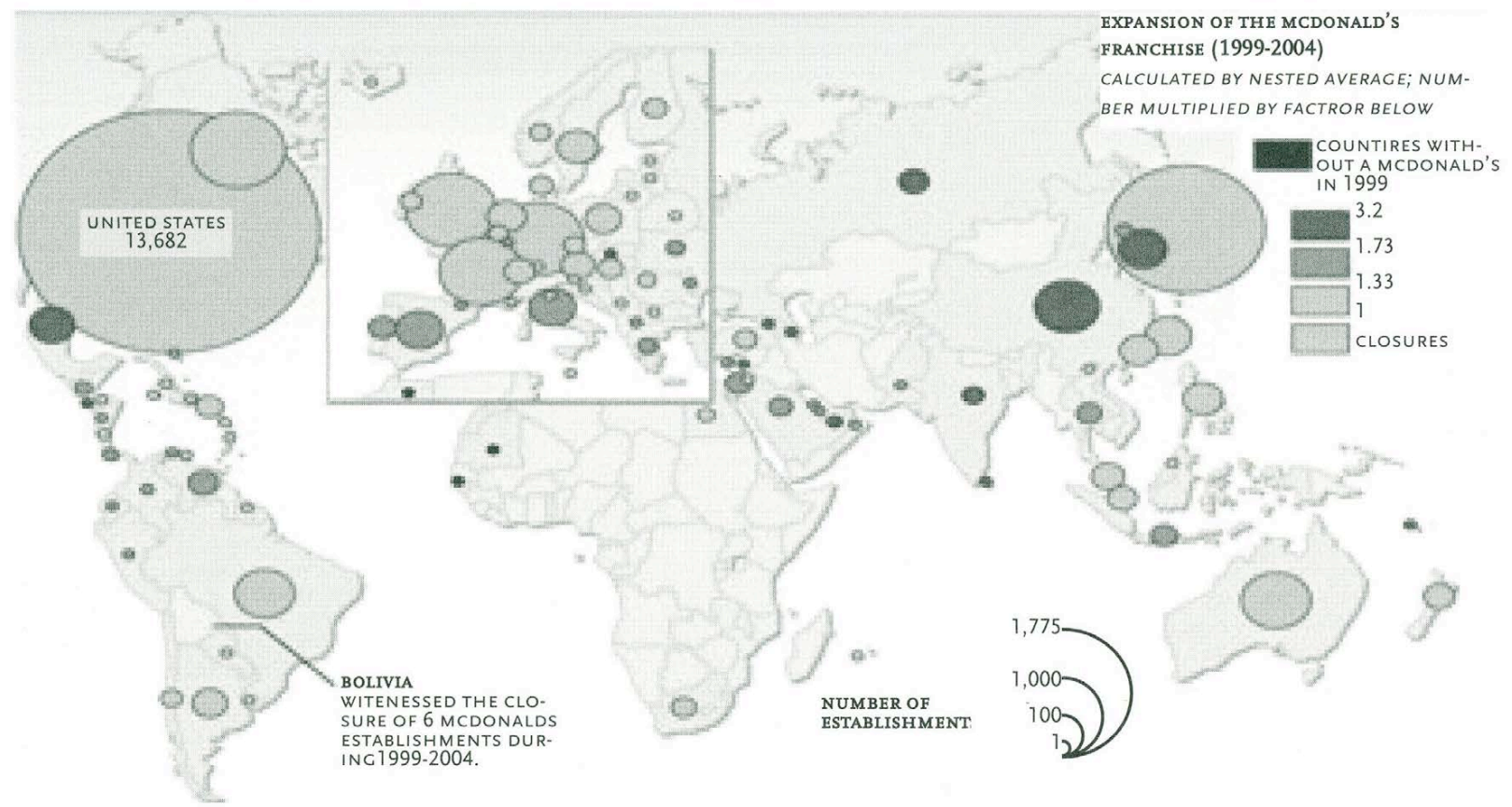

FIGURE 2: GLOBAL CALORIE CONSUMPTION AS OF 2002.

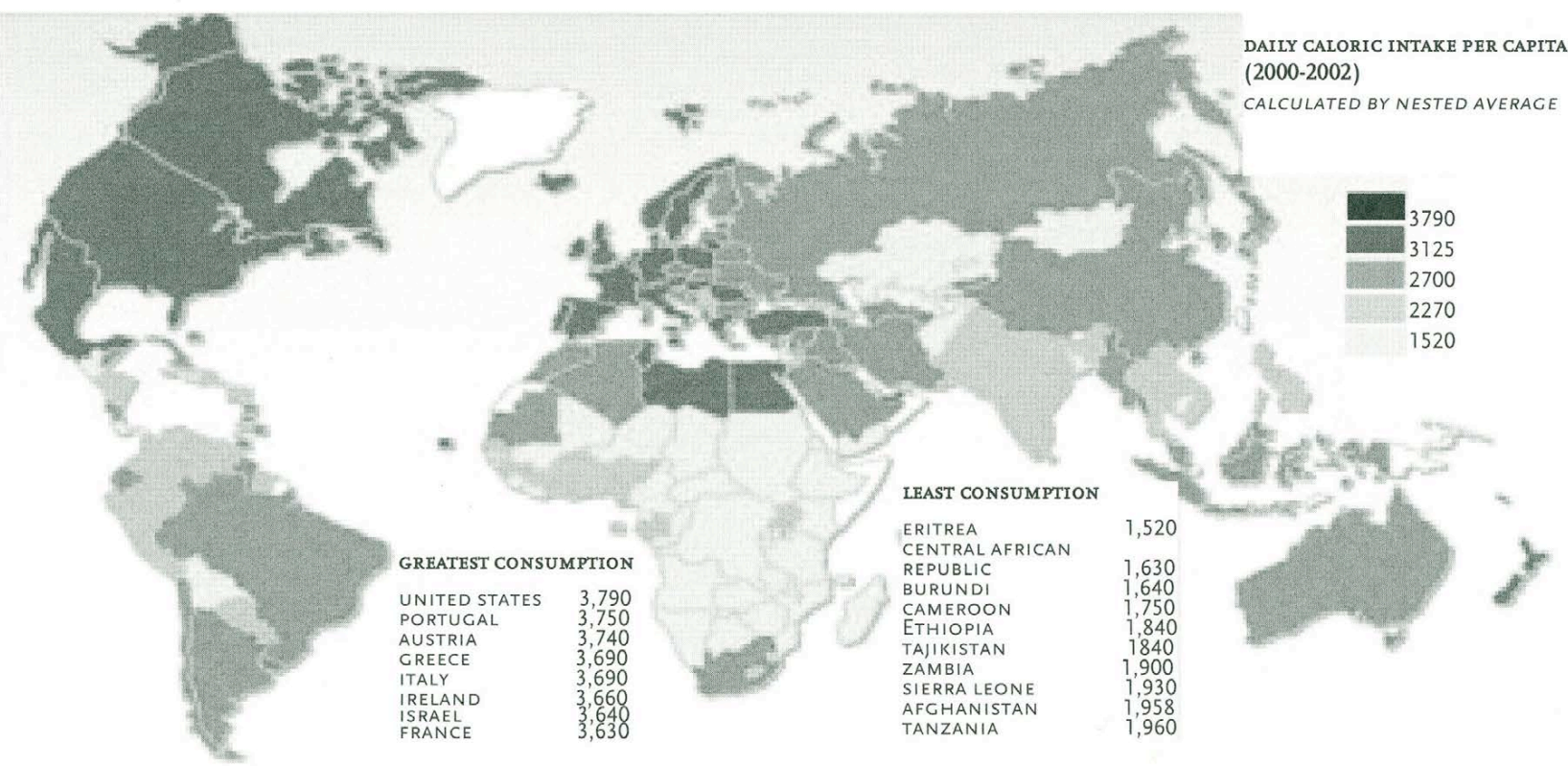


and sugar in greater quantities, and these daily caloric intake levels, if unused, store as fat in the body, as noted in Figure 2. Experts at the Ioth International Conference on Obesity pointed out that "overweight and obese people outnumber the undernourished in the world and childhood obesity is now on such a scale that for the first time in history, the human race is facing the possibility of millions of parents outliving their children." "ix Nutrition transition expert Barry Popkin points out the bleak fact that "in a decade, the energy density of food consumed by Chinese adults aged twenty to forty-five increased by over I3 percent." ${ }^{x}$ Increased consumption of cheaper and more readily available high fat, high calorie food and ingredients in China (and worldwide) have contributed to this alarmingly rapid rise in obesity.

\section{CHANGE TO URBAN LIFESTYLE EATING}

Urbanization is another factor contributing to this transition, since, "compared to rural dwellers, urban residents continue to consume higher levels of fats and animal foods, along with lower intakes of vegetables."xi Principle among the causes of this trend is the fact that the urban environment is one in which "a variety of Western style foods are supplied and promoted, and these consumers are both more inclined and better able to purchase these products."xii Delphine Zhu, a Sciences Po student from Shanghai, explained the enormous inequality between the city and country in China due to wages and available work. She described the emphasis on family in the country versus the individual in the city (which could promote the desire for status based on where and what is consumed). City populations are rising due to the lifting of restrictions on urban-rural migration, and the "rural labor force [response] to economic incentives by seeking employment in urban areas."xiii These migrants are known as "Mingong," which means peasant workers, according to Delphine.

Urban residents are increasingly drawn "to such relative intangible criteria as novelty, brand labels or other emotionally pleasing features of foods (feel goods)."xiv Delphine $\mathrm{Zhu}$ noted that there are "more choices and variety, more snacking, and more families going to restaurants" than in the past. Eating and socializing go hand in hand, not just in China but worldwide, and "as their rich and varied cuisine reflects, the Chinese love to eat . . China's rise in living standards is apparent at meal times. City residents, to whom even pork was once special, now regularly consume beef, fish, and shrimp."xv Popular western foods include "pizza, pasta, burgers and sandwiches," Delphine added. The younger generation seems to be buying into western habits more readily than their parents. She pointed out that "older people generally don't like using knives or forks so they find difficult to eat western food. They are loyal to Chinese cooking. I think it is mostly younger people and kids who like it. My mother hates cheese and she never understands my way of combining milk and cereals for breakfast!" She also noted that young people eat out more and tend to buy more pre-packaged lunches in their busy days. Modern grocery stores and twenty-four hour convenience stores are also appearing in cities, selling pre-packaged foods like those found in the West. China's recent foodsafety scares and the "SARS crisis of 2003 proved to be a boon for modern grocery formats, especially hypermarkets and convenience store chains, which have a strong reputation for cleanliness and quality control." xvi It is ironic that a health scare such as SARS has to some degree helped the image and popularity of "healthy" western-style grocery and convenience stores which sell and promote unhealthy foods. Urban sprawl has also cut into farm land to build homes and offices, and this real estate expansion not only in China but worldwide limits the amount of land available for farming and thus increases the price of healthier foods.

\section{LIFESTYLE CHANGES ADD TO THE PROBLEM}

The rate of obesity has grown the fastest in urban areas, with the childhood obesity rate doubling in the past ten

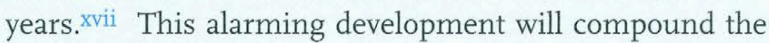
problem if left unaddressed, since "tastes and preferences begin to be established in early life."xviii Urban residents tend to adhere to the one-child-per-family policy in China due to the very limited living space available for families in 


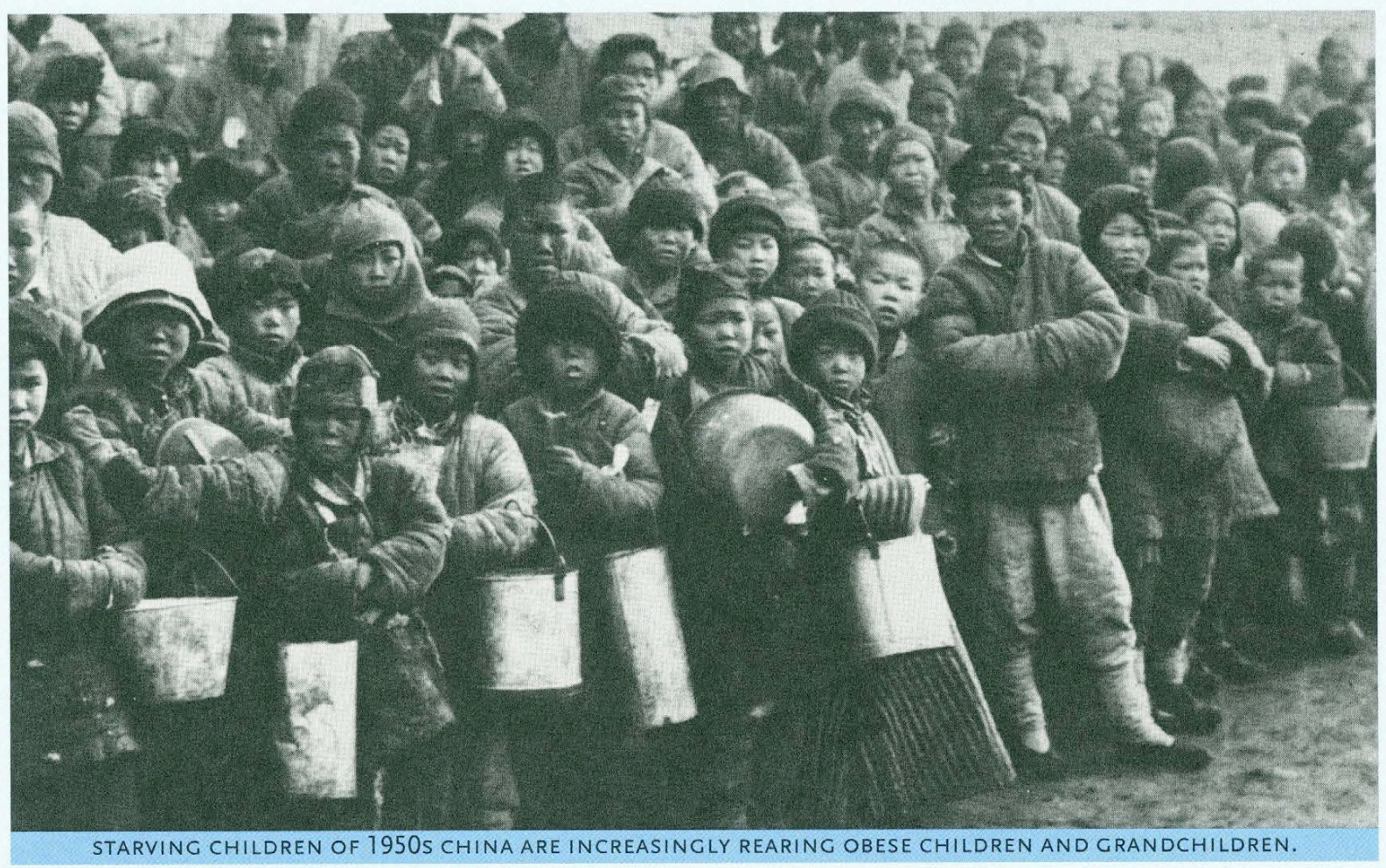

cities, whereas their rural counterparts are less inclined to follow these mandates given their more traditional views along with the practical desire for many sons to help on the farm. With only one child per family for most of the families in cities, and, consequently, the "many hopes riding on them . . . children with no siblings are usually spoiled by doting parents and even by grandparents [and are] dubbed "little emperors." xix It is not hard to imagine, therefore, the willingness of parents to give children large amounts of western foods. Advertisers target "kids in China [who] now have pocket money, and they spend a sizable portion of it on junk food ... Certain foods, such as new candies or fast food, have cachet."xx The new and enthusiastic foreign food companies in China take great, strategic efforts to win over young consumers and do "whatever they can to encourage even the youngest children to ask for advertised products in the hope of enticing young people to become lifetime consumers."xxi When asked whether she observes more obese children in Shanghai than previously,
Delphine said "not really in my everyday life, but the media says yes." She added that the prevalence of vending machines has increased "in big cities, yes, in transports, schools and other public places [but] I hardly used them unless I was very hungry."

Once obesity is acquired in childhood, it is very difficult to unlearn and undo the damaging eating and living lifestyle. Gigante explained that looking at the long-term consequences, "overweight adolescents have a 70 percent chance of becoming overweight or obese adults, which increases to 80 percent if one or more parent is overweight or obese." Addressing these problems early is critical to heading off the oncoming health crisis of China's next generation. "The Chinese Center for Disease Control and Prevention (CDC) released a guide to healthy eating for Chinese children and their parents in a direct attempt to slow rising childhood obesity levels."xxii Popkin agrees that "schools may provide an important opportunistic venue through 
which preferences for more healthy options can be encouraged."xxiii

Another cultural promotion of obesity is the attitude towards fat in China. The fact that "there is still a widespread belief that excess body fat represents health and prosperity, ... perhaps a consequence of China's recent history, where famine and chronic malnutrition caused the deaths of millions of people in the I950s," compounds the likelihood that some individuals will recognize the serious dangers of obesity.xxiv Such beliefs may actually increase the number of obesity cases among children and their parents and need to be addressed and dispelled by the government and healthcare professionals through increased education and public awareness of what is happening and, worse, what will eventually happen if left unaddressed and unresolved.

Luxury items which decrease activity levels are becoming more common in Chinese cities as well. For example, between 1989 and 1997, the number of households who owned cars increased by I4 percent. ${ }^{x x y}$ Owning a car increases the likelihood of being obese by " 80 percent . . . compared to those [households] who did not own a vehicle." Television ownership has also escalated, increasing inactivity during leisure periods.xxvi A study of attitudes and values concluded that "the most popular ways of spending leisure time include watching tv, surfing the internet, listening to music and reading [with] no significant differences in preferences due to age, education level, or income."xxvii All these new luxuries and attitudes toward leisure time reduce the amount of movement and general activity which burn excessive caloric intake and could prevent weight gain. City planning and layout in China should address the need for recreation areas as well to promote recreation. Currently, "the lack of consideration towards constructing environments in inner cities that promote physical activity has meant that it has become increasingly difficult to find safe places in residential areas to exercise or even walk," a deficiency which adds to the decrease in physical activity necessary to maintain appropriate body weight and overall health.xxviii This presents another opportunity for the government and private individuals to change the current movement to head off the oncoming trend.

Although the number of obese people in China do not yet rival that in the United States, the country with the largest population on Earth is headed for a major disaster. The group currently leading the obesity trend in China includes the "newly affluent and western-adapters . . . who broke most with the traditional food culture... [they are] to a large extent richer, more educated, and urban adults, as well as young adults." Indeed, the traditional Chinese diet, a primaraly vegetarian diet based on rice and vegetables, with moderate amounts of poultry, pork and seafood, creates a lower BMI overall. xxix The only explanation then for this explosion of obesity in China is the diet shifts from the traditional,healthy habits to the detrimental, western ones.

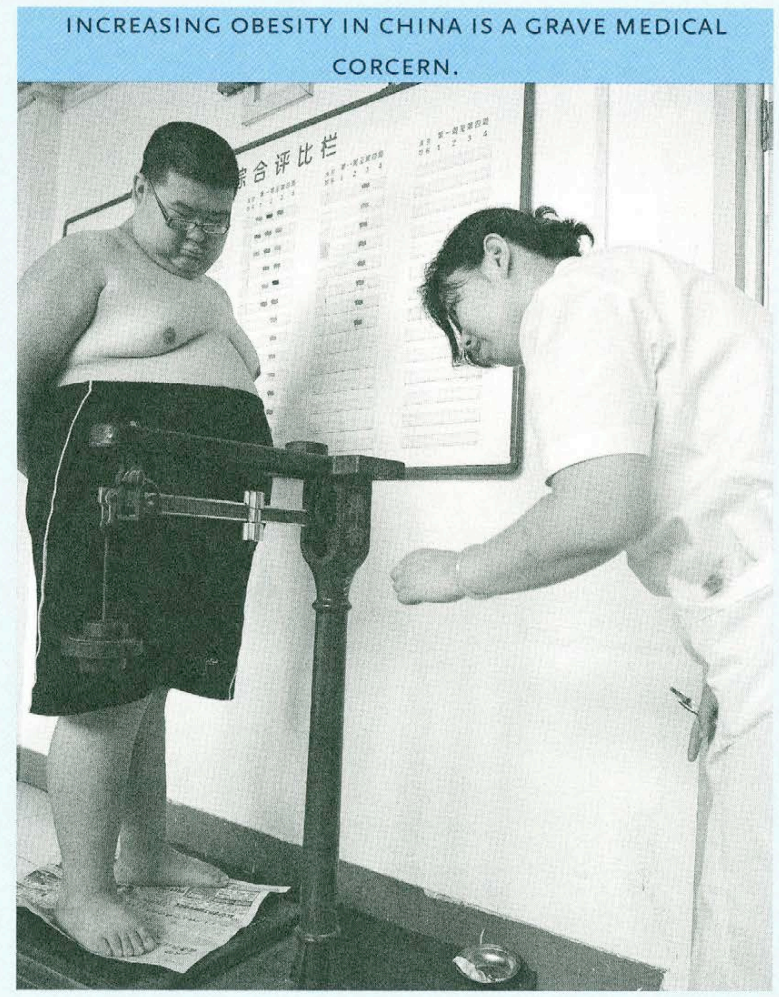




\section{GOVERNMENT ACTION COULD STOP THE}

\section{TREND}

The future for China depends on action and prevention taken today by the government and individuals. The consequences of economic growth and a more open-door policy in this case show there are both positives and negatives to globalization and economic expansion. It is encouraging to note that the Chinese government has apparently realized this reality given its recent "rejection [of the] 'go-for-growth' policy and turning to a more balanced and sustainable approach."xxx In a "people first" policy for a "well-off society" which uses economic growth to improve people's overall quality of life, we may yet see the crisis averted. Those who will be hit first with its consequences (the rich, young, and urban consumers) may be the pioneers in changing their western diet habits and reaffirming the "Chinese cultural value [of] extending and preserving life." Chinese culinary tradition reaching back several centuries has always appre-
Gigante stressed again the critical roles of governments, international partners, civil society and nongovernmental organizations and the private sector in shaping healthy environments and making healthier diet options affordable and easily accessible. Society's most vulnerable, the poor and children, must also be protected given they have limited choices about the food they eat and the environments in which they live. He further emphasized the responsibility of initiatives by the food industry itself to reduce the fat, sugar and salt content of processed foods as well as to increase employment of innovative, healthy, and nutritious choices, and to review current marketing practices could accelerate health gains worldwide.

The "nutrition transition" in China demonstrates the effects of globalization even on basic and culturally-rich traditions like the approach to and appreciation of food. China and other developing countries are beginning to experience the toll of their recently achieved economic and social sta-

\section{"Society's most vulnerable, the poor and children, must also be protected given they have limited choices about the food they eat and the environments in which they live."}

ciated the rapport between food and health. xxxi Gigante recommends individuals limit energy intake from total fats and shift fat consumption away from saturated fats to unsaturated fats, increase consumption of fruit and vegetables, as well as legumes, whole grains and nuts, limit the intake of sugars, and increase physical activity to at least thirty minutes of moderate-intensity activity on most days. More activity may be required for weight control. Such action by the government and individuals could prevent future cases of obesity in China and reverse others already in existence.

Nonetheless, other measures can be taken in this concerted effort to halt current and prevent future cases of obesity. tus. The economic boom has not protected them from the obesity trap posed by western-style eating habits and leisure activities. By contrast, the trend has shown that in higher-income households, eggs and meat are purchased more often and given more nutritional importance than grains. ${ }^{\text {xxxii }}$ Obesity is no longer any single country's problem, but a truly worldwide health crisis. Western experiences with obesity should serve as a warning and model of what has proven ineffective in addressing the crisis. The Communist state could potentially take action where western, democratic governments have been unwilling or unable to due to intense and effective lobbying by the food industry; a more hands on regulation of unhealthier foods and the simultaneous education about a more nutritional 
and holistic approach to diet and exercise. Banning junk food in schools, requiring clear and open labeling of the nutrition facts on all good products, taxing food products which are known to be unhealthy, promoting physical activity in schools and encouraging doctors to make recommendations during patient visits, and compelling restaurants to post the calories of each meal and highlight low-calorie options are all concrete ways in which this catastrophe can be avoided. While these solutions are universal, China in particular could work to counter the cultural myths surrounding fat, educate the one-child parenting population on obesity's damaging effects and work to reduce the urban-rural inequalities which drive an exodus from the countryside to the cities where obesity is more rampant due to fatty food availability and a more sedentary work and leisure-filled lifestyle.

Obesity is largely preventable and it costs far less to stay healthy than to regain one's health (or, in China's case, twenty-six million citizens' health). The social, economic, and human damages due to this global epidemic are truly horrific and far too high. Chinese citizens will suffer, but such losses will hurt the international community as well given the interdependent world in which we live. Taking action now against the causes is far better than dealing with the more difficult consequences down the road. Food is a basic need for every individual and thus this crisis is one in which all people can empathize. It is time for China and the world to seriously address this pressing disaster through several methods-education, awareness, regulations, and increased recreational areas in city-planning. The future of China's public health has a great weight in the global disaster. China is rapidly learning that "westernization" under globalization brings benefits and downsides. As Delphine reflected, "On the one hand, in terms of materiel consumption, China is 'westernizing', especially in some big cities like Beijing, Shanghai, and Guangzhou, [where] people are more and more materialist. On the other hand, Chinese people exclude a lot western cultures while maintaining a Chinese authenticity ... We are still isolated to certain extent from the world. The 'westerniz- ing' or 'modernizing' is superficial." This selective exclusion, this balance between westernizing and maintaining Chinese authenticity, in combination with collaborative, preventative action taken at different levels of society may be China's saving grace.

\section{ENDNOTES}

i. Zhang 2008

ii. "Weight Loss: Health Risks Associated with Obesity"

iii. Markey 2006

iv. Ibid.

v. "Global Strategy on Diet, Physical Activity Health"

vi. Zhang 2008

vii. Ibid.

viii. Lu 2004

ix. "More Fat People than Starving People in the World."

x. Nutrition Transition Presentation

xi. Popkin 2007

xii. Zhang 2008

xiii. Fleisher 2006

xiv. Zhang 2008

xv. Insight Guide China

xvi. "Grocery Retailing in China"

xvii. Markey 2006

xviii. Popkin 2007

xix. Insight Guide China

xx. Markey 2006

xxi. Nestle 2002

xxii. Lenton 2008

xxiii. Popkin 2007

xxiv. Wu 2006

xxv. Popkin 2007

xxvi. Ibid.

xxvii. Lu 2004

xxviii. Wu 2006

xxix. Zhang 2008

xxx. Ibid.

xxxi. Ibid.

xxxii. Ibid.

\section{REFERENCES}

Marie-Francoise Durand, Benoit Martin, Delphine Placidi, Marie Tournquist-Chesnier « Consommation de Calories 2002 »Atlas de Mondialisation, 2e Edition. (Paris : Presses de Sciences Po, 2007).

The Discovery Channel's Insight Guide China, ed. Scott Rutherford. (Singapore: Apa Publications, GmbH \& Co.: 200I).

Fleisher, Belton M. and Dennis Tao Yang, "Problems of China's Rural Labor Markets and Rural-Urban Migration" The Chinese Economy, 39(3) May-June 2006. 
Gigante, Dr. Joseph, Ph.D., Vanderbilt University Children's Hospital Physician and part-time teacher at Vanderbilt University Medical School.

PlanetRetail Ltd. 2006. "Grocery Retailing in China." Retrieved from <http://www.planetretail.net>.

Marie-Francoise Durand, Benoit Martin, Delphine Placidi, Marie Tournquist-Chesnier « Implementation des établissements McDonalds, 2004 ». Atlas de Mondialisation, $2 e$ Edition. (Paris : Presses de Sciences Po, 2007).

Lenton, Nina. 2008. "Childhood Obesity a Heavy Burden for Parents" Retrieved from <http://www.chinadaily.com.cn/china/2008I2/03/content_72654I5.htm>.

Lu, Le and Ilan Alon, "Analysis of the Changing Trends in Attitudes and Values of the Chinese: The Case of Shanghai's Young \& Educated," Journal of International and Area Studies $11(2) 2004$.

Markey, Sean. 2006. 'Obesity Explosion May Weigh on China's Future" National Geographic News Retrieved from $<\mathrm{http}$ //news.nationalgeographic.com/news/2006/08/060808 -china-fat.html>.

Nestle, Marion. Food Politics. (Berkley: University of California Press, 2002).

News-Medical.net. 2006. "More Fat People Than Starving in the World." Retrieved from <http://www.newsmedical.net/news/2006/09/04/19792.aspx>.

Popkin, Barry M. and Mendez, Michelle. "The Rapid Shifts in Stages of the Nutrition Transition: The Global Obesity Epidemic" in Globalization and Health edited by Ichiro Kawachi and Sarah Wamala, Oxford University Press: 2007.

Popkin, Barry M. "Nutrition Transition Presentation." University of North Carolina, Chapel Hill, School of Public Health. Retrieved from $<$ http://www.authorstream.com/Presentation/Woodwork588I4-Barry-Popkin-Nutrition-Transition-DepartmentNutritionThe-as-Education-ppt-powerpoint/>.

WebMD. 2009. "Weight Loss: Health Risks Associated with Obesity" Retrieved from <http://www.webmd.com/cholesterolmanagement/obesity-health-risks $>$.

World Health Organization 2008. "Global Strategy on Diet, Physical Activity Health" Retrived from <http://www.who.int/dietphysicalactivity/publications/facts/ob esity/en>.
Wu, Yangfeng, 2006. "Overweight and Obesity in China" BMJ. Retrieved from

<http://www.bmj.com/cgi/content/full/333/7564/362>.

Zhang, Xiaoyong, Hans Dagevos, Yuna He, Ivo van der Lans, Fengying Zhai, "Consumption and Corpulance in China: A Consumer Segmentation Study Based on the Food Perspective" Food Policy, 33(I). February 2008.

Zhu, Delphine, Sciences-Po, Paris Masters student from Shanghai, China 